\title{
МИНИСТЕРСТВО ТРАНСПОРТА В СИСТЕМЕ ОРГАНОВ ИСПОЛНИТЕЛЬНОЙ ВЛАСТИ
}

\section{THE MINISTRY OF TRANSPORT IN THE SYSTEM OF EXECUTIVE BODIES}

\begin{abstract}
In the present article the Author on the basis of comparative legal and system analysis of the Russian legislation and practice of the Ministry of Transport of the Russian Federation formulated the main directions of interaction of the Ministry of Transport with other Federal Executive Bodies, defined the basis of its legal status, systematized the existing powers and defined the main tasks of the Ministry in the medium term. The article also reflects the issues of financial support for the activities of the Ministry of Transport of Russia and the main indicators of improving the competitiveness of the transport system of Russia, as defined in the strategic planning documents.
\end{abstract}

Keyword: transport management, Ministry, Federal Executive Bodies, strategic planning

Ключевые слова: управление транспортом, министерство, федеральные органы исполнительной власти, стратегическое планирование

\section{Введение}

Министерство транспорта Российской Федерации является элементом единой системы федеральных органов исполнительной власти, составной частью её структуры. В этой связи весьма интересен вопрос о том, каким образом строятся взаимоотношения данного федерального органа исполнительной власти (далее - ФОИВ) с иными элементами системы.
Взаимодействие между элементами системы федеральных органов исполнительной власти может проявляться в различных формах, это может быть надзор и контроль за работой министерства или его подведомственными органами, координация работы, обмен информацией между элементами системы, и т.д.

Взаимодействие между федеральными органами исполнительной власти осуществляются, прежде всего, в форме документооборота, а также в форме проведения совместных мероприятий, создания координационных органов.

В литературе называются и такие формы взаимодействия, применительно к двум уровням вертикали исполнительной власти - федеральным органам исполнительной власти и органам исполнительной власти субъектов РФ:

- совместное осуществление правотворческой деятельности;

- совместную деятельность в рамках единой системы исполнительной власти;

- разработку и реализацию совместных программ и проектов на долевых началах;

- проведение совместных экспериментов;

- использование согласительных процедур [Краснов 2006, с. 14].

Применительно к Министерству транспорта РФ взаимодействие с ФОИВами реализуется при осуществлении согласованных действий по реализации 
отдельных государственных функций и оказанию государственных услуг на основании Приказа Минтранса России от 3 марта 2006 г. № 27 (ред. от 26.06.2017) «Об утверждении Регламента Министерства транспорта Российской Федерации», который предусматривает такие формы взаимодействия, как:

1. образование координационных и совещательных органов, в порядке, определяемом нормативными правовыми актами Президента Российской Федерации, Правительства Российской Федерации,

2. принятие согласованных или совместных актов Министерства с иными федеральными органами исполнительной власти, руководство деятельностью которых осуществляет Президент Российской Федерации или Правительство Российской Федерации.

Характерным примером взаимодействия Министерства транспорта РФ с иными федеральными органами исполнительной власти, являются взаимодействие, проходящее между Министерством транспорта Российской Федерации и Министерством финансов Российской Федерации. Так, согласно Постановлению Правительства РФ от 30 июля 2004 г. № 395 (ред. от 28.12.2018) «Об утверждении Положения о Министерстве транспорта Российской Федерации» Минтранс России имеет полномочия вносить в Министерство финансов Российской Федерации предложения по формированию федерального бюджета и финансированию подведомственной Министерству федеральных служб.

В данном случае речь идет о горизонтальном взаимодействии и взаимоотношениях ФОИВов. Но поскольку структура исполнительной власти иерархична, не менее важным является вопрос о вертикальном взаимодействии. На основании ст. 112 Конституции РФ Правительство РФ является высшим органом исполнительной власти.

Согласно Федеральному конституционному закону от 17 декабря 1997 г. № 2-ФКЗ «О Правительстве Российской Федерации», Правительство Российской Федерации в пределах своих полномочий в целях обеспечения сочетания интересов Российской Федерации и субъектов Российской Федерации по предметам совместного ведения Российской Федерации и субъектов Российской Федерации в сфере осуществления исполнительной власти координирует деятельность органов исполнительной власти, включая Министерство транспорта Российской Федерации.
В такой же мере Министерство транспорта РФ может осуществлять обратную связь с Правительством Российской Федерации. Так, согласно Постановлению Правительства РФ от 30 июля 2004 г. № 395 (ред. от 28.12.2018) «Об утверждении Положения о Министерстве транспорта Российской Федерации», в полномочия Министерства транспорта РФ входит возможность вносить на рассмотрение в Правительство Российской Федерации проекты федеральных законов, нормативных правовых актов Президента Российской Федерации и Правительства Российской Федерации и другие документы, по которым требуется решение Правительства Российской Федерации, по вопросам, относящимся к установленной сфере ведения Министерства и к сфере ведения подведомственных ему федеральных служб, а также проект плана работы и прогнозные показатели деятельности Министерства.

Подведомственные органы Министерства транспорта Российской Федерации находятся в ведении Министерства, что означает, что Министерство транспорта РФ осуществляет координацию и контроль деятельности подведомственных органов, в том числе подведомственных Министерству учреждений и организаций.

В ведении Министерство транспорта РФ состоят: 1 координируемая служба и 5 агентств, 11 подведомственных организаций, а также различные совещательные и координирующие органы.

\section{Рисунок 1. Подведомственные Минтрансу России федеральные органы исполнительной власти}

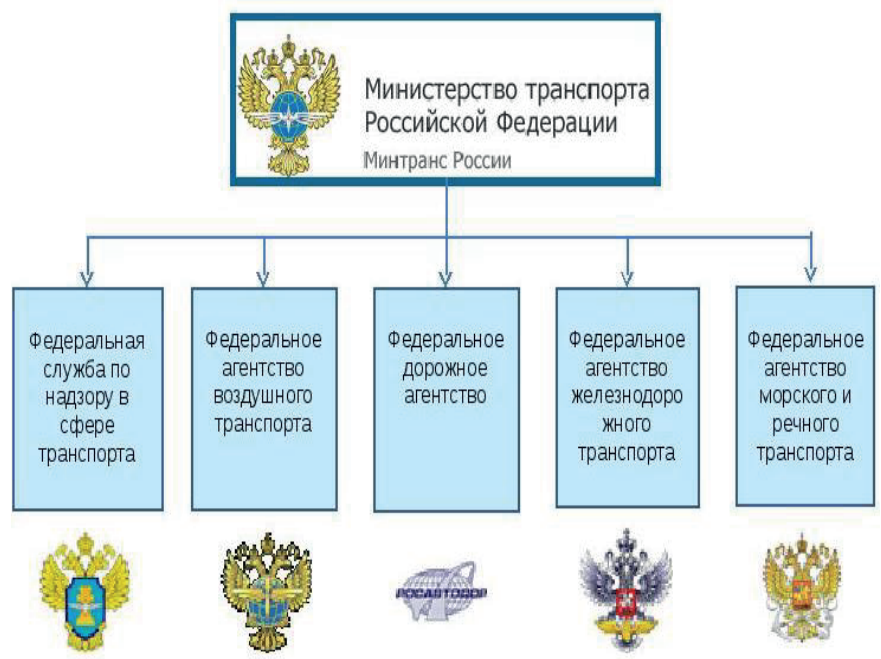

Источник: Собственная разработка. 
Таким образом, характеризуя взаимоотношения Минтранса с иными звеньями системы исполнительной власти следует отметить, что в рамках единой системы исполнительной власти Минтранс России как федеральное министерство осуществляет два вида взаимодействия - по вертикали (с Правительством Российской Федерации и подведомственными ему федеральной службой, 5 федеральными агентствами, 11 подведомственным предприятиями и учреждениями, территориальными органами Росавиации) и по горизонтали - с иными федеральными органами исполнительной власти. При этом используются различные формы и методы взаимодействия (в частности, образование координационных и совещательных органов, принятие согласованных или совместных актов Министерства с иными федеральными органами исполнительной власти, координация и контроль деятельности подведомственных ФОИВов и т.д.).

\section{Правовой статус Министерства транспорта РФ}

В настоящее время действует довольно широкий спектр нормативных правовых актов, регулирующих деятельность Министерства транспорта Российской Федерации, в числе которых Конституция Российской Федерации, нормы и принципы международного права, федеральные конституционные законы, федеральные законы, акты Президента, Правительства Российской Федерации, а также акты Минтранса и иных ФОИВов. Большинство федеральных законов, регулирующих транспортную сферу, составляют кодифицированные акты в различных отраслях управления транспортом, включая Воздушный кодекс РФ, Кодекс торгового мореплавания, Кодекс внутреннего водного транспорта РФ, а также уставы: железнодорожного транспорта, автомобильного транспорта и городского наземного электрического транспорта. В перечисленных законодательных актах урегулировано разграничение полномочий между различными видами федеральных органов исполнительной власти по управлению транспортной отраслью.

Поскольку Министерство транспорта Российской Федерации находятся в ведении Правительства Российской Федерации, большинство его статусообразующих актов утверждены Правительством Российской Федерации, среди них постановления Правительства РФ: от 30 июля 2004 г. № 395 (ред. от 28.12.2018) «Об утверждении Положения о Министерстве транспорта Российской Федерации; от 11 июня 2004 г. № 274 (ред. от 28.12.2018) «Вопросы Министерства транспорта Российской Федерации; от 28 мая 2008 г. № 399 (ред. от 28.01.2011) «О некоторых вопросах деятельности Министерства транспорта Российской Федерации».

Наряду с актами, содержащими нормы материального права, определяющими статус федерального министерства, действует значительное число актов, содержащих процессуальные, процедурные нормы, определяющие порядок реализации принадлежащих ФОИВам функций и полномочий, к которым относятся, в первую очередь регламенты (Типовой регламент взаимодействия ФОИВов, Регламент Министерства транспорта Российской Федерации, утвержденный Приказом Минтранса России от 3 марта 2006 г. № 27 (ред. от 26.06.2017), административные регламенты осуществления государственных функций и оказания государственных услуг).

В законодательстве Российской Федерации детально урегулированы такие вопросы правового статуса федерального министерства, как его цели и задачи, сферы ведения, функции и полномочия, также используется термин «права» (ФОИВ вправе...). При этом в различных нормативных правовых актах нет единых подходов в использовании терминологии, одни и те же правомочия могут иметь разные наименования - «функция», сфера деятельности (ведения). Для наглядности приведем пример смешения понятий. Пункт 5.11(7) Положения о Министерстве транспорта Российской Федерации, содержащийся в разделе II Постановления Правительства РФ от 30 июля 2004 г. № 395 (ред. от 28.12.2018) «Полномочия» содержит следующую формулировку «осуществляет функции государственного заказчика».

Как отмечалось выше, элементом правового статуса министерства являются его функции. Современное разграничение функций системы федеральных органов исполнительной власти было установлено в Указе Президента РФ от 9 марта 2004 г. № 314 «О системе и структуре федеральных органов исполнительной власти» [Собрание законодательства РФ. 2004. № 11. Ст. 945]. Данным Указом определено, что федеральные органы исполнительной власти могут иметь следующие функции: по выработке и реализации государственной политики в установленной сфере деятельности; принятию нормативных правовых актов; контролю и надзору; управлению государственным имуществом; оказанию государственных услуг.

Так, основной целью деятельности федеральных министерств являются участие в выработке и реализация государственной политики и нормативное 
правовое регулирование в установленной сфере деятельности, федеральные службы осуществляют государственный контроль и надзор; федеральные агентства призваны организовать оказание государственных услуг и управление государственным имуществом.

По замыслу разработчиков реформы необходимо было осуществить типизацию государственных функций и разделение их между федеральными министерствами, службами и агентствами [Вишняков 2011, c. 9]. Однако на практике система федеральных органов исполнительной власти пока не обладает четко выраженной функциональной определенностью. Данное обстоятельство не раз отмечалось учеными-административистами [Старилов 2004, с. 4].

Применительно к Министерству транспорта РФ наблюдается нарушение распределения функций. Так, не смотря на установленное в Указе Президента Российской Федерации № 314 закрепление функций по нормативно-правовому регулированию за федеральными министерствами, Приказом Минтранса России от 3 марта 2006 г. № 27 (ред. от 26.06.2017) «Об утверждении Регламента Министерства транспорта Российской Федерации» [Бюллетень нормативных актов федеральных органов исполнительной власти. 08.05.2006. № 19.] на данное Министерство возложили функцию по управлению государственным имуществом, оказанию государственных услуг в сфере обустройства государственной границы Российской Федерации, создания, развития и обеспечения деятельности пунктов пропуска через государственную границу Российской Федерации и мест пересечения государственной границы Российской Федерации.

Следующим элементов правового статуса выступают полномочия министерства, совокупность которых образует его компетенцию. Говоря о проблемах действующего российского законодательства, определяющего компетенцию федеральных органов исполнительной власти, Заверткина Е.В., Куракин А.В., Карпухин Д.В. отмечают, что ключевой проблемой является отождествление дефиниций «функция федерального органа исполнительной власти» и «полномочие федерального органа исполнительной власти» в нормативных правовых актах, Приводя пример абз. «г» П. 3 Указа Президента Российской Федерации № 314 , где в качестве функции федерального органа исполнительной власти определено осуществление координации и контроль деятельности находящихся в его ведении федеральных служб и федеральных агентств [Заверткина, Куракин, Карпухин 2018, c. 17-22]. Для реализации указанной функции министру предоставляются функции, которые, в сущности, являются полномочиями, так как отражают юридически значимые действия, посредством которых осуществляется функция координации. Так, министр «утверждает ежегодный план», «вносит в Правительство Российской Федерации проект положения», «вносит в Министерство финансов Российской Федерации предложения», «вносит в Правительство Российской Федерации проекты», «дает поручения», «контролирует исполнение».

Перечень полномочий Минтранса урегулирован довольно широким спектром нормативных правовых актов, включая кодексы, регламентирующие отдельные виды транспорта, указы Президента РФ, устанавливающие общее разграничение функций между различными видами ФОИВов, постановления Правительства РФ, определяющие статус подведомственных ему органов, включая Минтранс России. Самый детальный перечень полномочий содержится в Постановлении Правительства РФ от 30 июля 2004 г. № 395 (ред. от 28.12.2018) «Об утверждении Положения о Министерстве транспорта Российской Федерации».

Характеризуя данной нормативный акт, следует отметить значительный объем закрепленных полномочий (по самым приблизительным подсчетам п. 5-6 Положения о Минтрансе содержат порядка 200 позиций), это при том, что перечень полномочий в них является исчерпывающим. В положении имеется запретительные нормы, в частности, связанные с реализацией функции по контролю и надзору.

Классификацию полномочий Министерства транспорта РФ, изложенных в указанном положении можно осуществлять по следующим основаниям:

1. по характеру полномочий (к примеру, правотворческие, обобщение и анализ правоприменительной практики, осуществление государственных закупок и т.д.),

2. по сферам правового регулирования (в первую очередь, используется критерий отраслевого управления - воздушный, водный, железнодорожный, морской транспорт, транспортная инфраструктура, транспортная безопасность и т.д.),

3. по правовой форме принятых решений (по принимаемым актам управления (правила, положения, административные регламенты, инструкции и т.д). 


\section{Задачи по развитию транспортной}

\section{отрасли на среднесрочную перспективу}

Принятие Федерального закона от 28 июня 2014 г. № 172-Ф3 (ред. от 31.12.2017) «О стратегическом планировании в Российской Федерации» стало импульсом для издания Правительством РФ нормативных документов стратегического и программного характера, в их числе Транспортная стратегия Российской Федерации на период до 2030 года, государственная программа Российской Федерации «Развитие транспортной системы» и ряд других программ. Данные документы, а также публичные декларации ключевых целей и приоритетных задач Министерства транспорта Российской Федерации на 2017 и 2018 годы определили основные цели и задачи развития транспортной системы на среднесрочную перспективу, а также основные результаты, которых необходимо достичь в различных областях транспортной области.

Необходимо отметить, что в документах стратегического планирования и принятых на их основе нормативных правовых актах Минтранса России сформулированы основные цели и задачи деятельности данного ФОИВа, а также ключевые показатели, которых необходимо достичь в среднесрочной перспективе. В этой связи хотелось бы остановиться на некоторых результатах, которые были достигнуты в транспортной отрасли по реализации задач, закрепленных в публичных декларациях ключевых целей и приоритетных задач Министерства транспорта Российской Федерации на 2017 и 2018 годы (см. Таблицу 1).

\section{Таблица 1. Показатели реализации Плана деятельности Министерства транспорта Российской Федерации на 2016 - 2021 годы}

\begin{tabular}{|c|c|c|c|}
\hline \multirow{2}{*}{ показатель } & \multicolumn{2}{|c|}{ план } & \multirow{2}{*}{$\begin{array}{c}\text { исполнение } \\
2 \\
\end{array}$} \\
\hline & 2017 & 2018 & \\
\hline транспортная подвижность населения & $\begin{array}{c}\text { 7,9 тыс. пасс.-км } \\
\text { на } 1 \text { человека }\end{array}$ & $\begin{array}{c}8,5 \text { тыс. пасс.-км } \\
\text { на } 1 \text { человека }\end{array}$ & $\begin{array}{c}8,1 \text { тыс. пасс.-км } \\
\text { на } 1 \text { человека }\end{array}$ \\
\hline на транспорте общего пользования & $\begin{array}{c}\text { 3,5 тыс. пасс.-км } \\
\text { на } 1 \text { человека }\end{array}$ & $\begin{array}{c}\text { 3,9 тыс. пасс.-км } \\
\text { на } 1 \text { человека }\end{array}$ & $\begin{array}{c}\text { 3,8 тыс. пасс.-км } \\
\text { на } 1 \text { человека }\end{array}$ \\
\hline перевозка пассажиров на железнодорожном транспорте & $\begin{array}{c}\text { 1043,3 млн. } \\
\text { пассажиров }\end{array}$ & $\begin{array}{c}\text { 1053,8 млн. } \\
\text { пассажиров }\end{array}$ & $\begin{array}{c}\text { 1121,2 млн. } \\
\text { пассажиров }\end{array}$ \\
\hline В пригородном транспорте & $\begin{array}{c}\text { 938,5 млн. } \\
\text { пассажиров }\end{array}$ & $\begin{array}{c}\text { 952,3 млн. } \\
\text { пассажиров }\end{array}$ & $\begin{array}{c}\text { 1018,9 млн. } \\
\text { пассажиров }\end{array}$ \\
\hline $\begin{array}{l}\text { рост авиационной подвижности населения на региональных } \\
\text { и местных авиалиниях к уровню } 2011 \text { года }\end{array}$ & $165,6 \%)$ & & $190,0 \%$ \\
\hline $\begin{array}{l}\text { перевезено на внутренних региональных авиалиниях, за исключе- } \\
\text { нием маршрутов, пунктом назначения/отправки которых являет- } \\
\text { ся г. Москва; }\end{array}$ & $\begin{array}{l}11,39 \text { млн. } \\
\text { пассажиров }\end{array}$ & 11,84 млн. & $\begin{array}{l}\text { 14,32 млн. } \\
\text { пассажиров }\end{array}$ \\
\hline $\begin{array}{l}\text { обеспечение возможности перевозки в прямом смешанном сооб- } \\
\text { щении на территорию Республики Крым и города федерального } \\
\text { значения Севастополя и в обратном направлении }\end{array}$ & $\begin{array}{c}369 \text { тыс. } \\
\text { пассажиров }\end{array}$ & $\begin{array}{c}338 \text { тыс. } \\
\text { пассажиров }\end{array}$ & $\begin{array}{c}369 \text { тыс. } \\
\text { пассажиров }\end{array}$ \\
\hline $\begin{array}{l}\text { ввод в эксплуатацию после строительства и реконструкции авто- } \\
\text { мобильных дорог федерального значения }\end{array}$ & $326,2 \mathrm{kм}$ & 854,3 км & 347,4 км \\
\hline $\begin{array}{l}\text { ввод в эксплуатацию автомобильных дорог федерального значе- } \\
\text { ния на условиях государственно-частного партнерства }\end{array}$ & 69,5 км & 569,7 км & 69,5 км \\
\hline $\begin{array}{l}\text { ввод в эксплуатацию дополнительных главных путей и новых же- } \\
\text { лезнодорожных линий }\end{array}$ & 146,8 км & 231,9 км & 248,7 км \\
\hline $\begin{array}{l}\text { прирост производственной мощности российских морских пор- } \\
\text { тов в объеме }\end{array}$ & 22 млн. тонн & 28,0 млн. тонн & 22 млн. тонн \\
\hline $\begin{array}{l}\text { ввод в эксплуатацию после реконструкции взлетно-посадочных } \\
\text { полос (в аэропортах г. Ростова-на-Дону (Платов), Саранска, Екате- } \\
\text { ринбурга, Кызыла, Краснодара (Пашковский), Чокурдах) }\end{array}$ & 4 & 10 & 6 \\
\hline
\end{tabular}

Источник: Собственная разработка на основании данных Министерства транспорта Российской Федерации. 
Из приведенной таблицы следует, что в запланированные на 2017 г. показатели в подавляющем своем большинстве были перевыполнены, за исключением таких показателей, как прирост производственной мощности российских морских портов, ввод в эксплуатацию автомобильных дорог федерального значения на условиях государственно-частного партнерства и перевозок пассажиров в Республике Крым и городе федерального значения Севастополе, что свидетельствует об эффективности работы органов исполнительной власти в сфере транспорта.

Также в 2017 г. был апробирован социальный стандарт транспортного обслуживания населения при осуществлении перевозок пассажиров и багажа автомобильным транспортом и городским наземным электрическим транспортом в г. Калининграде в рамках реализации Программы ООН / Глобального экологического фонда / Министерства транспорта Российской Федерации «Сокращение выбросов парниковых газов от автомобильного транспорта в городах России».

Издан ряд нормативных документов Минтранса России: приказ от 8 декабря 2017 г. № 513 «О порядке определения начальной (максимальной) цены контракта, а также цены контракта, заключаемого с единственным поставщиком (подрядчиком, исполнителем), при осуществлении закупок в сфере регулярных перевозок пассажиров и багажа автомобильным транспортом и городским наземным электрическим транспортом» и распоряжение от 15 декабря 2017 г. № НА-229-р «Об утверждении Методики определения начальной (максимальной) цены контракта, заключаемого с поставщиком (в том числе с единственным), при осуществлении закупок в сфере регулярных перевозок пассажиров и багажа автомобильным транспортом и городским наземным электрическим транспортом».

Говоря о перспективах развития транспортной отрасли и задачах по нормативно-правовому регулированию, необходимо отметить Постановление Правительства РФ от 20 декабря 2017 г. № 1596 (ред. от 28.12.2018) «Об утверждении государственной программы Российской Федерации «Развитие транспортной системы»», которым была утверждена соответствующая федеральная программа. Сроки и этапы реализации Программы рассчитаны на период 2018 - 2021 годов.

Общий объем финансирования Программы составляет 7753331 296,8 тыс. рублей, в том числе:

- на 2018 год - 2066758 735,6 тыс. рублей;

- на 2019 год - 1867073 636,3 тыс. рублей;

- на 2020 год - 1848709 478,5 тыс. рублей;

- на 2021 год - 1970789 446,4 тыс. рублей.
Рисунок 2. Финансирование государственной программы «Развитие транспортной системы»

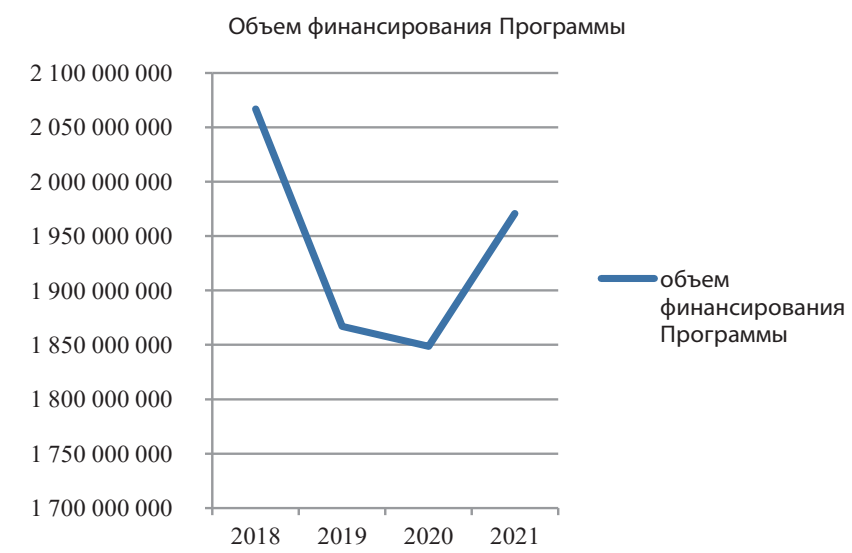

Источник: Собственная разработка на основании данных программы Российской «Развитие транспортной системы».

Программа содержит ряд стратегических целей развития транспортной отрасли и устанавливает основные показатели, которых нужно достичь на среднесрочную перспективу с 2016 по 2021 годы.

Цель 1 - ускорение товародвижения, снижение транспорт емкости экономики до 26,3 т-км на 1000 рублей внутреннего валового продукта (уточняется в соответствии с параметрами прогноза социально-экономического развития на 2019 год и плановый период 2020 и 2021 годов).

\section{Рисунок 3. Транспортоемкость экономики в госу- дарственной программе «Развитие транспортной системы»}

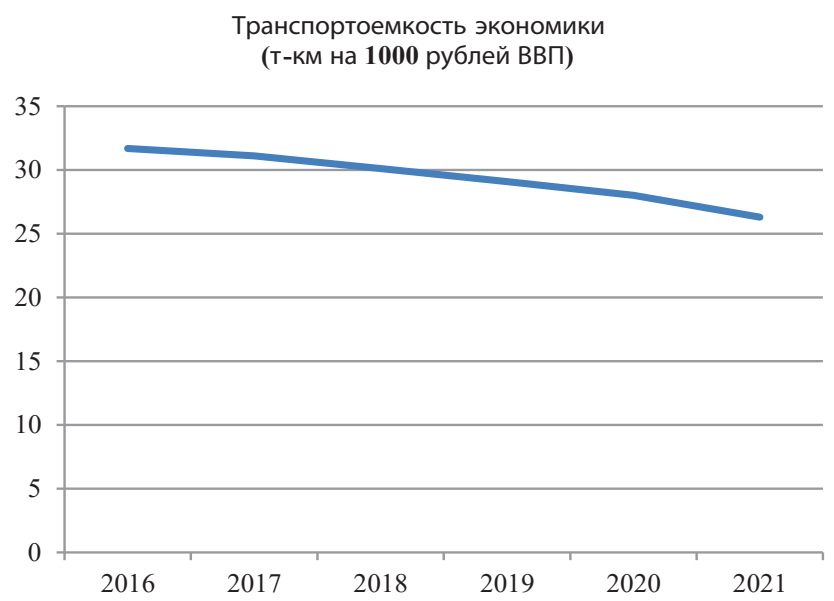

Источник: Собственная разработка на основании данных программы Российской Федерации «Развитие транспортной системы». 
Цель 2 - повышение доступности качественных транспортных услуг для обеспечения транспортной подвижности населения на уровне 4,2 тысяч пассажир километров на 1 жителя (уточняется в соответствии с параметрами прогноза социально-экономического развития на 2019 год и плановый период 2020 и 2021 годов).

Рисунок 4. Транспортная подвижность населения (тыс. пасс.-км на 1 жителя)

(тыс. пасс. -км на 1 жителя)

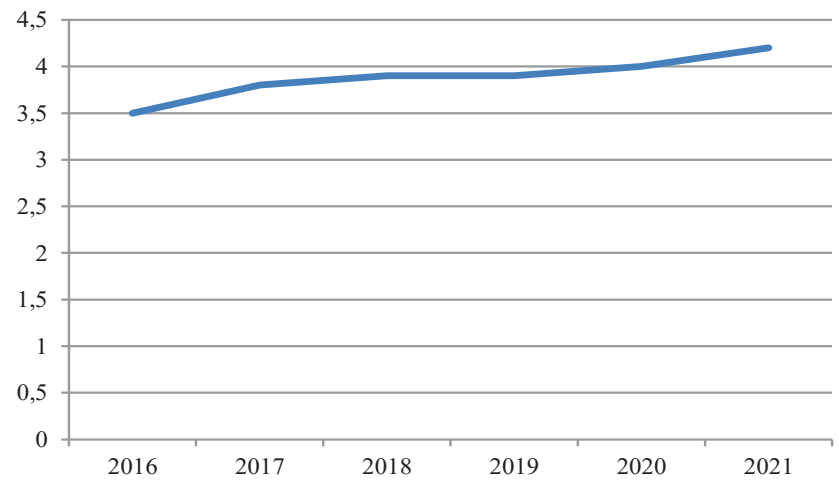

Источник: Собственная разработка на основании данных программы Российской Федерации «Развитие транспортной системы».

Цель 3 - повышение конкурентоспособности транспортной системы России на мировом рынке транспортных услуг и рост экспорта транспортных услуг до 19 млрд. долларов США.

\section{Рисунок 5. Экспорт транспортных услуг}

(млрд. долларов США)

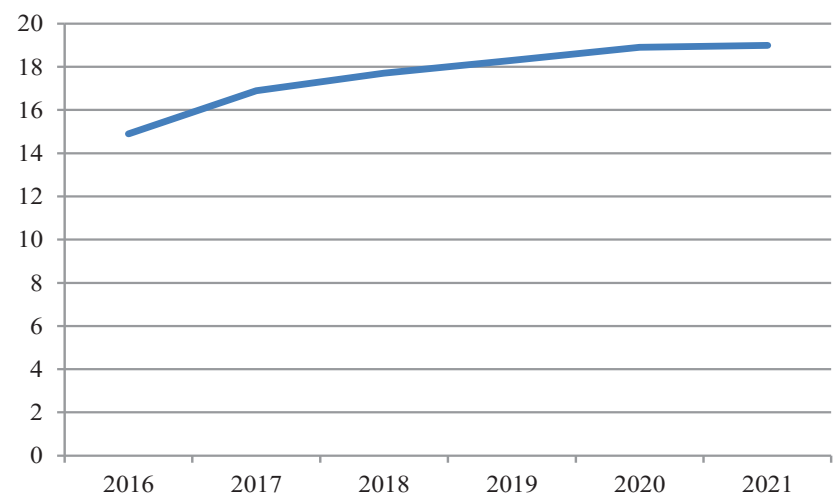

Источник: Собственная разработка на основании данных программы Российской Федерации «Развитие транспортной системы».
Цель 4 - повышение комплексной безопасности и устойчивости транспортной системы с целью сокращения числа происшествий на транспорте на единицу транспортных средств на 10 процентов по отношению к уровню 2016 года.

Рисунок 6. Показатели транспортной безопасности Сокращение числа происшествий

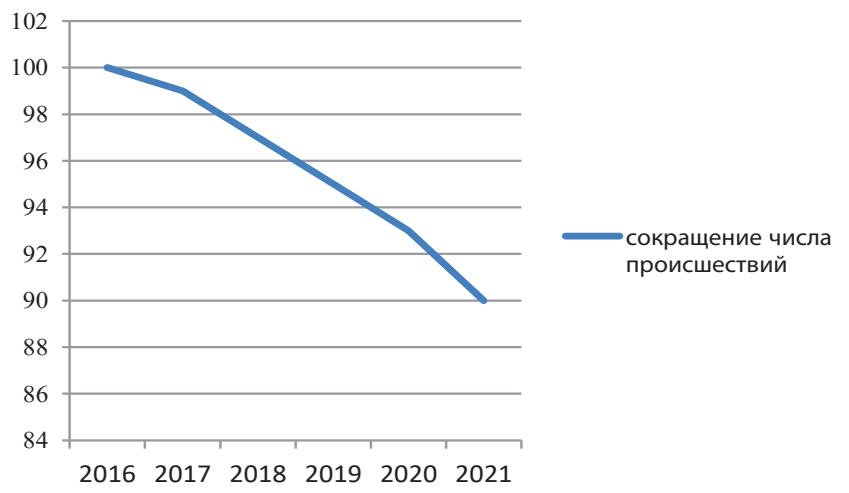

Источник: Собственная разработка на основании данных программы Российской Федерации «Развитие транспортной системы».

Цель 5 - снижение доли протяженности дорожной сети городских агломераций, работающих в режиме перегрузки в «час-пик», до 68 процентов.

\section{Рисунок 7. Снижение транспортной нагрузки в городах-агломерациях}

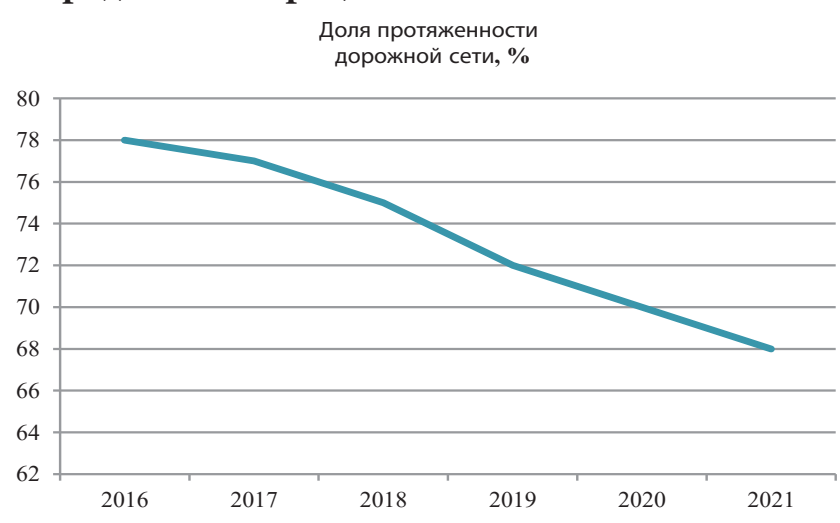

Источник: Собственная разработка на основании данных программы Российской Федерации «Развитие транспортной системы».

\section{Заключение}

В «Национальных целях и стратегических задачах развития Российской Федерации на период до 2024 года» поставлен ряд важнейших задач в сфере 
экономического развития, включая вхождение Российской Федерации в число 5 крупнейших экономик мира, обеспечение темпов экономического роста выше мировых при сохранении макроэкономической стабильности, в том числе инфляции на уровне, не превышающем 4\%.

Решение данных задач невозможно без развития транспортной системы и инфраструктуры нашего государства, поскольку Россия занимает первое место в мире по площади своей территории, что требует создания эффективной и удобной для хозяйствующих субъектов и граждан системы транспортного обеспечения жизнедеятельности населения.

Однако в последние годы в стране появились существенные ограничения роста экономики, обусловленные недостаточным развитием транспортной системы. В Транспортной стратегии Российской Федерации отмечается, что сегодняшние объемные и качественные характеристики транспорта, особенно его инфраструктуры, не позволяют в полной мере и эффективно решать задачи растущей экономики, в том числе задачи удовлетворения спроса инновационного сектора на высококачественные транспортно-логистические услуги.

В настоящее время существует ряд нерешенных и общесистемных проблем развития транспортной отрасли Российской Федерации, к числу которых можно отнести:

1. территориальные и структурные диспропорции в развитии транспортной инфраструктуры,

2. недостаточный высокий уровень:

- доступности транспортных услуг и мобильности населения;

- экспорта транспортных услуг, в том числе использования транзитного потенциала;

- обеспечения транспортной безопасности;

3. недостаточно высокое качество транспортных услуг,

4. усиление негативного влияния транспорта на экологию.

Все это требует существенной перестройки не только организации транспортной системы и инфраструктуры, но и внедрения в систему управления транспортной отраслью инновационных и эффективных методов руководства. Решение указанных задач невозможно без создания адекватной поставленным стратегическим целям системы правового регулирования управленческих отношений в сфере транспорта, что предопределяет повышение роли и значения деятельности Министерства транспорта Российской Федерации, как органа уполномоченного осуществлять нормативно-правовое регулирование в указанной области.

\section{Библиография}

Вишняков В.Г. (2011), Административная реборма: 15 лет поисков концепции, «Законодательство и экономика» no. 7.

Доклад о реализации в 2017 г. Плана деятельности Министерства транспорта Российской Федерации на 2016 - 2021 годы [online], www.mintrans.ru/documents.

Заверткина Е.В., Куракин А.В., Карпухин Д.В. (2018), Проблемь разграничения функиий федеральньх органов исполнительной власти как итог административной ребормы, «Современное право» по. 1.

Краснов М.А. (2006), Поиск оптимальной модели единой системы исполнительной власти, [в:] Е.Л. Наумова (ред.), Исполнительная власть; проблемь организаизи и деятельности, Москва.

Старилов Ю.Н. (2004), Административная реборма: способствует ли она совершенствованию административно-правового регулирования? Административное и административно-процессуальное право: Сборник статей, Москва.

\section{Список правовых актов}

Федеральный конституционный закон от 17 декабря 1997 г. № 2-ФКЗ (ред. от 28.12.2016) «О Правительстве Российской Федерации», Собрание законодательства РФ. (1997. № 51. Ст. 5712).

Указ Президента РФ от 9 марта 2004 г. № 314 «О системе и структуре федеральных органов исполнительной власти», Собрание законодательства РФ. (2004. № 11. Ст. 945).

Указ Президента РФ от 7.05.2018 N 204 (ред. от 19.07.2018) «О национальных целях и стратегических задачах развития Российской Федерации на период до 2024 года», Собрание законодательства РФ. (2018. № 20. Ст. 2817).

Постановление Правительства РФ от 20 декабря 2017 г. № 1596 (ред. от 28.12.2018) «Об утверждении государственной программы Российской Федерации «Развитие транспортной системы»», Собрание законодательства РФ. (2018. № 1 (Часть II). Ст. 340).

Распоряжение Правительства РФ от 22.11.2008 N 1734-р (ред. от 12.05.2018), Собрание законодательства РФ. (2008. № 50, ст. 5977). Собрание законодательства РФ. (2008. № 52 (ч. 2) (поправка)).

Приказ Минтранса России от 3 марта 2006 г. № 27 (ред. от 26.06.2017) «Об утверждении Регламента Министерства транспорта Российской Федерации», Бюллетень нормативных актов федеральных органов исполнительной власти. (№ 19. 08.05.2006). 